\title{
LA ANTROPOLOGÍA MUSICAL: INFORME SOBRE SUS OBJETIVOS Y TRABAJOS DE INVESTIGACIÓN*
}

Wolfgang SuPPAN

Graz

\begin{abstract}
Since 1951, when the German philosopher Hans Plessner published his paper about «Anthropology of Music», some people in different scholarly disciplines tried to find out, how man and music are fundamentally interlaced. Viktor Zuckerkandl's «Sound and Symbol» (1956) and «Man the Musician» (1973), Alan B. Merriams «Anthropology of Music» (1964), John Blackings «How Musical is Man?» (1973), Wolfgang Suppans «Der musizierende Mensch. Eine Anthropologie der Musik» (1984) and «Musica humana» (1986) are the most important steps into a new and interdisciplinary science of music. But thinking on the need of music for man and society starts in old Chinese and Greek philosophy. Our research report and bibliographical survey about the development of anthropological studies in music pays also attention to the Spanish Jesuit P. Antonio Eximeno y Pujades, who published in the 18th century in his nearly unknown books important ideas on our topic.
\end{abstract}

\section{Resumen}

Desde 1951 en que el filósofo alemán Hans Plessner publicó su artículo «Anthropology of Music», se ha intentado descubrir desde diferentes disciplinas cómo se interrelacionan el ser humano y la música. Los libros Sound and Symbol (1956) y Man the Musician (1973) de Viktor Zuckerkandl, Anthropology of Music (1964) de Alan B. Merriam, How Musical is Man? de John Blacking (1973), Der musizierende Mensch. Eine Anthropologie der Musik (1984) y Musica humana (1986) de Wolfgang Suppan constituyen los pasos más importantes hacia una nueva e interdisciplinaria ciencia de la música. Pero el pensar sobre la necesidad de la música por parte del hombre y la sociedad aparece ya en las antiguas filosofías de China y Grecia. Nuestro estudio y repaso bibliográfico sobre el desarrollo de la investigación antropológico-musical toma asimismo en consideración al jesuita español P. Antonio Eximeno y Pujades, quien en el siglo XVIII publicó en sus poco conocidos libros importantes ideas sobre nuestra temática.

«El que sólo se dedica a una disciplina aisladamente ha renunciado ya a la posibilidad de llegar a una definición existencial de su investigación, y con ello también, y sobre todo, al planteamiento de la cuestión de la definición del sentido de la ciencia en general» (Richard Schwarz). ${ }^{1}$

* Traducción: Dr. Helmut Brenner y Teresa Martín Goyena.

1. Richard Schwarz, Prinzipien einer interdisziplinären Forschung, en: Die deutsche Universitätszeitung, Jg. 1971, Nr. 24, págs. $805-810$, cita pág. 807. 
En el año 1997, en el Instituto de Etnomusicología de la Escuela Superior de Música y Arte Dramático de Graz (Austria), se aprobó una tesis de doctorado que trataba de los escritos de Antonio Eximeno y Pujadas, nacido en 1729 en Valencia. ${ }^{2}$ El estudio presentaba como título: Una Antropología Musical del Siglo XVIII. ¿Por qué «Antropología Musical»? Eso es una denominación de una disciplina que a todas luces es de fecha más reciente, ya que obviamente la idea surgió por primera vez en 1945, cuando Frank Howes escribió en los Proceedings del Royal Anthropological Institute: «Music is an anthropological phenomen. A tune is as much a human fact as a ritual dance or a cranial measurement». ${ }^{3}$ En 1951 se publicó la primera aportación concreta al tema, el artículo del filósofo alemán Helmuth Plessner «Zur Anthropologie der Musik» («Sobre la antropología de la música») ${ }^{4}$ a la cual, poco después, todavía en los años 50, le siguió la observación de Werner Danckert que valdría la pena crear, en un futuro cercano, una antropología de la música. ${ }^{5}$

Alan P. Merriam publicó en 1964, obviamente sin conocimiento de estos escritos (ni de ninguna de las antropologías de las ciencias humanísticas y naturales europeas), una «Anthropology of Music», ${ }^{6}$ la cual, como resultado del trabajo en equipo en uno de los departamentos de Antropología Cultural de una universidad estadounidense, no podía de ninguna manera satisfacer las esperanzas que tenían los representantes de las disciplinas antropológicas europeas en un trabajo de ese tipo. Walter Wiora indicó, con relación a esto, que la dedicación al Humanum, el desarrollo de aquella anthropology of music que contempla la música en el contexto de la vida, debería contar como interés básico de la musicología. Sin embargo, la idea principal, ya inherente a este término, tendría que ser, realizar la antropología como ciencia del ser humano en un sentido mucho más amplio de lo que había sido hasta ese momento. ${ }^{7}$ En este lado del Atlántico el libro de Merriam se estima pero se lo ve más bien como una introducción a la etnomusicología bajo la especial consideración de «use and function» de la música, ${ }^{8}$ mientras al otro lado del Atlántico todavía se lo considera como «foundational» (fundacional) para la investigación antro-

2. Dietmar Haas, Eine Anthropologie des 18. Jahrhunderts. Band 1: Kommentar zu Eximenos Schriften über die politische Bedeutung der Beziehung zwischen römischer Virtus und griechischer Arete in Abhängigkeit vom anthropologischen Ursprung in der sprechenden und singenden Ausdrucksweise, Band 2: Übersetzung von Antonio Eximenos dell'origine e delle regole della musica colla storia del suo progresso, decadenza, e rinnovazione ins Deutsche, Graz 1996, Tesis de Doctorado en Filosofía en la Escuela Superior de Música y Arte Dramático de Graz/Institut für Musikethnologie 1996, manus. (en imprenta); en el texto citado como: Haas (con números romanos para el tomo y arábigos para la página).

3. Frank Howes, en: Proceedings of the Royal Anthropolocial Institute, MAN 14, Sept.-Oct. 1945, Nr. 83, págs. 107-108. Probablemente ya en la misma dirección apuntó la mención hecha por Rudolf Virchows en la Sociedad Antropológica de Berlín en el año 1886 cuando dijo que: «la falta de la investigación de la prehistoria de la música es la única laguna en las aspiraciones de la sociedad»; véase: Carl Stumpf, Die Anfänge der Musik, Leipzig 1911, pág. 7.

4. Helmuth Plessner, Zur Anthropologie der Musik, en: Jahrbuch für Ästhetik und allgemeine Kunstwissenschaft 1951 , págs. 110-121.

5. Albrecht Schneider, Vergleichende Musikwissenschaft als Morphologie und Stilkritik: Werner Danckerts Stellung in der Volksliedforschung und Musikethnologie, en: Jahrbuch für Volksliedforschung 24, 1979, págs. 11-27.

6. Alan P. Merriam, The Anthropology of Music, Evanston 1964, 2/1968, 3/1971.

7. Walter Wiora, Volksmusik und Musica humana, en: Yearbook of the International Folk Music Council 7, 1975, pág. 30. La opinión de Wiora también la comparte: Anya Peterson Royce, The Anthropology of Dance, Bloomington/London 1977. Para la interpretación de Wiora véase también: Wolfgang Suppan, Walter Wiora [artículo necrológico], en: Studia musicologica 38, 1997, págs. 229-233.

8. Kurt von Fischer, Zur Anwendung der musikethnologischen Begriffe von «Use» und «Function» auf die historische Musikwissenschaft und Musikgeschichtsschreibung, en: Die Musikforschung 30, 1977, págs. 148-151. 
pológica musical, ${ }^{9}$ junto con «How musical is man?» de John Blacking. ${ }^{10}$ A diferencia de Merriam, Blacking, como profesor de la Universidad de Belfast en Irlanda del Norte, tomaba muy bien en cuenta la tradición académica europea y sabía, además, cómo conectar (casi tejer) la tradición musical de los pueblos indígenas con la historia de la música de la Europa occidental. En uno de sus trabajos mencionó a Viktor Zuckercandl, ${ }^{11}$ cuyos textos, como otros, tampoco han sido tomados en cuenta por la antropología cultural estadounidense (y eso, que casi todos fueron publicados en inglés y en los Estados Unidos). ${ }^{12}$ Que en los Estados Unidos se omitan los textos referentes a la antropología musical publicados en alemán, incluso después de los años 60, ya no se puede explicar únicamente como un problema de idioma. Quizás hay otra razón (esta suposición no se debe soslayar): ¿Se tratará de dos disciplinas distintas cuando los americanos hablan de «anthropology» y los europeos de «Anthropologie»?

En el presente artículo el autor tratará de aclarar esta pregunta, sobre todo en el mismo sentido que Carl Friedrich von Weizsäcker quien intentó avanzar a partir de las diseminadas ciencias solitarias dedicadas a problemas antropológicos hacia una «antropología completa», con la intención de «interrelacionar paradigmas científicos entre sí e iniciar un diálogo entre ellos» («wissenschaftliche Paradigmata miteinander in Kontakt, ins Gespräch zu bringen»). ${ }^{13}$ También Adolf Portman piensa en una antropología pragmática, una antropología sencilla y básica, cuando exige una teoría completa del ser humano. ${ }^{14}$

Eso es fundamental, porque se trata del hombre desde que los seres humanos son capaces de pensar: en los escritos de Confucio, Alfarabi, Aristóteles, Platón, de los Neoplatónicos como Boethius, en las obras de Tomás de Aquino y de Goethe; el auténtico estudio de la humanidad es el hombre, leemos en «Wahlverwandtschaften» de este último (1809). En este sentido, hablamos de una «antropología» la cual se pregunta qué es el ser humano —antropología teórica - y de qué es capaz - antropología práctica- Las preguntas surgen a través de las disciplinas humanísticas, científicas, teológicas y jurídicas y también de la (ciencia de la) música.

De hecho ya fue un concepto antropológico musical, cuando Confucio (551 a 479 a.C.) describió la música como expresión de lo inmutable de los sentimientos. La música, según él, ennoblece el espíritu de los seres humanos, mantiene su corazón en equilibrio y domina los anhe-

9. Regula Burckhardt Qureshi, Music Anthropologies and Music Histories: A Preface and an Agenda, en: Journal of the American Musicological Society 48, 1995, págs. 331-342.

10. John Blacking, How Musical is Man?, Seattle 1973

11. John Blacking, Towards a Human Science of the Tonal Art: Anthropology and the Reintegration of Musicology, en: Musikethnologische Sammelbände 12 = Schladminger Gespräche zum Thema Musik und Tourismus, editado por Wolfgang Suppan, Tutzing 1991, págs. 9-16.

12. Viktor Zuckerkandl, Man the Musician, Princeton, N. J. 1973. sobre Zuckerkandl véase: Wolfgang Suppan, «Musik der Menge». "Volk» und «Volksmusik», in den Schriften Heinrich Schenkers und seines Schülers Viktor Zuckerkandl, en: Festschrift Walter Wiora zum 90. Geburtstag, ed. por Christoph-Hellmut Mahling y Ruth Seiberts, Tutzing 1997, págs. 471-491; ídem., Viktor Zuckerkandls «Homo Musicus», en: Festschrift für Oskar Elschek, Wien/Bratislava 1997 (en imprenta).

13. Carl Friedrich von Weizsäcker, Der Garten des Menschlichen. Beiträge zur geschichtlichen Anthropologie, München/Wien 1977, pág. 17.

14. Adolf Portmann, Vom Lebendigen. Versuche zu einer Wissenschaft vom Menschen, Frankfurt/M. 1973, pág. 110. Más sobre ello en: Hans Rössner (Ed.), Reproduktion des Menschen. Beiträge zu einer interdiziplinären Anthropologie, Berlin u. a. 1981. 
los y las pasiones. Sólo el que esté posesionado de la música correcta es capaz de acercarse al conocimiento verdadero. Escuchar música no sólo significa observar las propiedades físicas de los sonidos, sino introducirse en los pensamientos que la música puede evocar. La música y la ética son finalmente lo mismo, ambas tienen el objetivo de dirigir los deseos del pueblo hacia una meta común y proporcionar un orden. Confucio pensaba poder reconocer por medio de la música, si un Estado estaba en todo su esplendor o en decadencia. Porque: «cuando un pueblo está en confusión se olvida la ética, y la música se vuelve inmoderada [...]». Reinar sobre los hombres y gobernarlos bien, presupone, de acuerdo a la creencia de Confucio, «vigilar las inclinaciones y las aversiones de los hombres e influenciarlas a través de la música». ${ }^{15}$ Por eso, la reforma del estado se basaba en gran medida en la normatividad de la música.

El comportamiento de los grandes pensadores de la antigua Grecia no era distinto. La escuela de Pitágoras le adjudica tareas específicas a la música en la educación y en la formación de los seres humanos. Así como en el ámbito indio y árabe determinados Ragas y Maqamat pueden generar estados emocionales y con ello ser capaces de influenciar el comportamiento y el pensamiento del ser humano. De la misma manera, los autores griegos informan de una música que es capaz de evocar estados de éxtasis y de otra música que a través de la gradación hasta la descarga es capaz de calmar de nuevo (Katharsis). Se atribuye a Pitágoras el descubrimiento de que la música se basa en leyes numerales y con ellas se explican las misteriosas relaciones entre la música y el ser humano. Adecuadas Tropoi (Harmoniai) dirigen el estado físico y psíquico del ser humano y generan en los jóvenes determinados hábitos éticos.

En la Politeia de Platón Sócrates menciona a Damón, cuando habla de la música apta para el Estado en relación con el ritmo: los cambios en los Tropoi musicales van, según Damón, siempre a la par con los profundos cambios políticos. Eso, sin embargo, tiene un asombroso paralelismo con los conceptos de Confucio. ${ }^{16}$ Vestigios de esta forma de pensar se encuentran tanto en el imperio romano como en los inicios de la sociedad occidental: el neoplatónico Boethius (alrededor de 480 a 524), canciller de Teodorico en Roma, expone en sus libros, De institutione musi$c a$, la música como arte universal que es capaz de relacionar la comprensión de la verdad racional con la formación ideológica. La música es según Boethius parte de la ética práctica, porque los sonidos se perciben por el oído no sólo en forma juiciosa y comparativa, sino también con alegría o con miedo. Así como las matemáticas, la música posee un carácter precientífico y un ethos propedéutico, a través del cual mejora la capacidad de pensamiento y la primera experiencia del auténtico ser. Boethius distingue la música mundana, la música humana y la música instrumental. La música humana estaría anclada en el mismo ser humano: en la unión armónica de cuerpo y espíritu. ${ }^{17}$

15. Hans Oesch y otros, Der chinesische Kulturbereich, Außereuropäische Musik I, Laaber 1984 (Neues Handbuch der Musikwissenschaft, Band 8), págs. 3-96, cita pág. 27.

16. Hermann Abert, Die Lehre vom Ethos in der griechischen Musik, Leipzig 1899; A. J. Neubecker, Altgriechische Musik. Eine Einführung, Darmstadt 1977 (Die Altertumswissenschaft).

17. Günther Wille, Musica romana. Die Bedeutung der Musik im Leben der Römer, Amsterdam 1967. 
En pueblos indígenas al igual que en las culturas clásicas de las distintas épocas, el ser humano, se acerca cantando, tocando y bailando a lo sobrenatural, al mundo de los dioses y los demonios, o al Dios único, porque «la música es el lenguaje de los dioses», como me percaté por primera vez en los años 60 en mis investigaciones en Africa Occidental y, más tarde, también en Jamaica. «Si observamos, en general, los movimientos religiosos y las orientaciones de la humanidad parece que ha habido dentro de ellos una relación extremamente cercana entre lo mítico y lo musical. Es como si la mística simplemente necesitara de la música - ya sea como medio para expresar las experiencias y las visiones que están demasiado lejanas del entendimiento diario para poder expresarlas en palabras; como técnica para la concentración interna y la meditación; o como generador de un éxtasis y de la unión del alma con lo trascendente» (Hanoch Avenary). ${ }^{18}$ Tal sabiduría se transmitió del antiguo testamento al nuevo, y con ello al pensar y sentir del occidente cristiano.

Lo mucho que se consideró además del valor estético, el valor de utilidad de la música para el ser humano y para la sociedad desde Johann Joseph Fux y Georg Friedrich Händel, y de éstos hasta la Epoca Clásica Vienesa de un Joseph Haydn y Wolfgang Amadeus Mozart, ${ }^{19}$ lo atestigua Antonio Eximeno (1729-1808) quien en la musicología, hasta ahora, se conoce solamente por las polémicas en contra de las autoridades más importantes de su tiempo: Fux, Eiler, Tartini, Rameau y d'Alambert, así como por el pleito con el Padre Martini. ${ }^{20}$ Sin embargo José Subirá ya señaló que los escritos de Eximeno, sobre todo su «Dell'origine» editado en Roma en 1774, sobresalen no solamente por su atrevimiento con el cual declaró la guerra a las opiniones tradicionales acerca de la relación de la música con las matemáticas, sino que también «se presenta la diferencia básica entre las reglas fundamentales de las matemáticas y las de la música, que son meramente resultados de la observación: es suficiente que el compositor siga su instinto natural; las reglas son innecesarias para componer. Con esto Eximeno preparó el terreno a las visiones sobre la música de los comienzos del romanticismo alemán (Herder, Heine, Wackenroder)» (Subirá). ${ }^{21}$ Esto significa que él tenía un punto de vista antropológico de la música al reconocer como componente el «instinto natural».

La tesis de doctorado de Dietmar Haas sobre Eximeno anteriormente mencionada (nota 2), en la cual por primera vez se ha realizado una traducción completa de Dell'origine e delle

18. Hanoch Avenary, Encounters of East and West in Music: Selected Writings, Tel Aviv 1979, pág. 165. Más sobre ello también en: Wolfgang Suppan, Ansätze und Ideen zur Anthropologie der Musik, en: Orbis Musicae $10=$ Essays in Honor of Hanoch Avenary, Tel Aviv 1990/91, págs. 248-271.

19. Wolfgang Suppan, Die «Neue Melodik» als zentrales Merkmal klassischer Musik, en: Internationaler Musikwissenschaftlicher Kongreß zum Mozart-Jahr 1991 Baden-Wien, Tutzing 1993, págs. 255-265; ídem., Möglichkeiten und Grenzen (musik-)kultureller Traditionsbildung: Von Johann Joseph Fux zu Wolfgang Amadeus Mozart, en: Europa im Zeitalter Mozarts, ed. por Moritz Csáky y Walter Pass, Wien/Köln/Weimar 1995, págs. 33-38. Ambos ensayos también publicados en: Jahresgabe Nr. 17 der Johann-Joseph-Fux-Gesellschaft, Graz 1994.

20. Robert Stevenson, artículo «Eximeno», en: New Grove 6, 1980 (reimpreso 1993), pág. 323; G. Stefani, Padre Martini e l'Eximeno: bilancio di una celebre polemica sulla musica di chiesa, en: Journal of the American Musicological Society 10, 1957, págs. 477-485; Dietmar Haas, Antonio Eximenos allgemeine Kritik am «Gradus ad Parnassum», en: Auf Fux-Jagd. Mitteilungsblatt der Johann-Joseph-Fux-Gesellschaft Graz/Österreich, Jg. 5, Nr. 2, Dez. 1997, págs. 154-161.

21. José Subirá, «Eximeno», en: MGG 3, 1954, columnas 1651-1652. 
regole della musica al idioma alemán, ${ }^{22}$ atestigua y refuerza ese punto de vista de Subirá. Eximeno, se declara como un representante de los aristoxanos y como un adversario de los pitagóricos, cuyo pensamiento circulaba durante toda su vida alrededor del esclarecimiento de la relación entre teoría y práctica: «¿A qué nos atendremos, pues? ¿A la observación o al cálculo? ¿Al raciocinio o a la experiencia?, ¿A la teoría o a la práctica?», se pregunta el día 16 de mayo de 1764 a los 46 años de edad ante la Corte Real Española, al completo, en su discurso de la inauguración de la Real Academia Militar en Segovia, en la cual se instaló como primer profesor y rector inaugural —como se diría hoy en día- (Haas I/118). En Dell'origine... se encuentra, diez años después, su credo: «la teorica forma l'uomo savio, la pratica lo rende esecutore; e colla pratica senza la teorica non si può divenire se non che esecutore ignorante» (ibídem). «Secondo Aristosseno adunque le ragioni e le proporzioni numeriche sono fondamento falso della Musica, smentito anche dalla sperienza. Gl'intervalli [...] si devono determinare colla sperienza dell'udito, la cuale sperienza è il principio, in cui deve l'intelletto fondarsi per raziocinare della Musica. Eccovi in Aristosseno il principio della Filosofia sperimentale, col quale si trattano al dì d'oggi le materie fisiche, e del quale mi sono io servito nella mia Opera sull' Orig. e le regole della Musica'» (Haas I-106) ${ }^{23}$ Esto lo explica Eximeno a través de la comparación con el idioma: «appunto come nelle lingue, la Gramatica delle quali c'insegna bensì ad evitare gli errori sostanziali; ma per parlarle con eleganza non si può prescrivere regola alcuna infallibile. Questo è il punto, nel quale trionfa la practica: senza l'esercizio di parlare o di scrivere una lingua non si può arrivar a parlarla con eleganza. Ma neppur basta la practica nè per le lingue nè per la Musica; v'abbisogna in oltre la nativa disposizione del genio o dell'istinto, che c'ispiri la combinazione di parole o di suoni più adattati al soggetto, di che si tratta [...] In conclusione la vera teorica musicale deve ricavarsi, come la teorica delle lingue, dalla stessa practica» (Haas I/119).

En este contexto Eximeno habla sobre lo «popolare» en el arte y explica finalmente el buen gusto y el mal gusto (tanto en las artes en general como en la música): «La complessione, l'educazione, l'idee, i pregiudizj dispongono l'animo di ciascuno a dilettarsi più d'un oggetto che d'un altro. Ma tra questa infinita varietà di gusti ve n'è uno, che si chiama buon gusto, il quale consiste nel piacere de vedere o sentire espressa al vivo la Natura» (Haas I/138). Como una experiencia clave describe Eximeno la visita de una misa en la catedral de San Pedro en Roma durante la fiesta de Pentecostés en el año 1770, en la cual se cantó «Veni Sancte Spiritus» de Niccolò Jomellis: «[...] y juntamente con el músico iba yo recitando para mí las mismas palabras con aquel fervor y energía con que las hubiera recitado al pueblo para conmoverlo y exitar su devoción, cuando advertí que mi voz hacía una modulación, aunque oscura, muy semejante a la del músico. Nadie puede imaginarse de qué claridad me sentí entonces iluminado acerca de la música; parecióme salir de una oscura gruta al aire puro del mediodía. Con que la música,

22. Raphael Georg Kiesewetter tradujo los escritos de Eximeno sólo parcialmente en su libro: Der neuen Aristoxaner zerstreute Aufsätze, Leipzig 1846.

23. La diferencia entre las escuelas de Pitágoras y de Aristoxenes con respecto a la música las explica: A. J. Neubecker, Altgriechische Musik. Eine Einführung, Darmstadt 1977. 
decía yo para mí, no es más que una prosodia para dar al lenguaje gracia y expresión» (Haas I/147). La «voz cantante» de Eximeno se desarrolla de la declamación emocionalmente cargada; los instrumentos musicales, sin embargo, hacían posible la imitación artificial del canto: «Gli strumenti sono riguardo alla voce umana l'istesso che le pitture riguardo a gli oggetti naturali; e siccome un Pittore, che facesse studio sopra le pitture senza volgere giammai lo sguardo a gli oggetti naturali, difficilmente copiarebbe al vivo la Natura; egualmente il Compositore di Sonate, che non abbia gusto sul canto della voce umana, difficilmente comporrà di buon gusto» (Haas I/165-166).

El modo de pensar de Eximeno se expuso tan detalladamente porque - aun hasta ahora no ha sido reconocido- le dio una influencia muy importante al desarrollo de la estética en la Ilustración y continuó más allá de la Ilustración, hasta Friedrich von Hausegger — véase las comparaciones de los textos en Haas Y/144- Como resultado de eso nació una moderna antropología musical, basada en las Ciencias Naturales, e introduciendo conocimientos biológicos en las ciencias humanas. ${ }^{24}$

En un tiempo en que en la contemplación del arte se empieza a separar obras de efectos, lo cual sucede relacionado con la expansión de la cultura de la letra durante la Ilustración, ${ }^{25}$ Johann Gottfried Herder habla - en el sentido de Eximeno- sobre la música como un arte enérgico, por lo que no se deben contemplar solamente las obras (erga) sino en primer lugar los efectos (en-ergeia) ${ }^{26} \mathrm{El}$ adversario de Herder en Königsberg, Immanuel Kant, veía eso de otra manera: a pesar de que desde el Renacimiento a menudo se encuentran indicios de una forma de contemplación inmanente al arte (en la pintura, las artes gráficas y plásticas más claramente que en la música y en las artes dramáticas o en la arquitectura), pone en la «Kritik der ästhetischen Urteilskraft» (Crítica del discernimiento estético) ${ }^{27}$ la primera piedra para lo que posteriormente - con Théophile Gautier — se denominará L'art pour l'art-Ästhetik, que rápidamente empezará a difundirse y cubrir enteramente la estética de la utilidad (Gebrauchsästhetik) ${ }^{28}$. Las ideas de Kant y de Gautier acerca de un arte, al cual se le niega un interés utilitario y que tiende a una belleza autónoma, se encuentran trasladadas a la música en los conceptos de Eduard Hanslick.

24. Wolfgang Suppan, Der musizierende Mensch. Eine Anthropologie der Musik, Mainz 1984 (Musikpädagogik. Forschung und Lehre 10); ídem., Musica humana. Die anthropologische und kulturethologische Dimension der Musikwissenschaft, Wien 1986 (Forschen - Lehren - Verantworten. Festgaben zur 400-Jahr-Feier der Karl-Franzens-Universität Graz, 8).

25. Sobre el hecho de que la escritura frenó el desarrollo del idioma pero sobre todo de la música en la cultura occidental, véase: Wolfgang Suppan, Musiknoten als Vorschrift und als Nachschrift, en: Symbolae Historiae Musicae. Hellmut Federhofer zum 60. Geburtstag, Mainz 1971, págs. 173-183; ídem., Musik und Schrift. Was kann und was soll Musiknotenschrift (in der Pädagogik) leisten?, en: Erziehungs- und Unterrichtsmethoden im historischen Wandel, Bad Heilbrunn/Obb. 1986, págs. 152-163.

26. Véase también: Richard von Mises, Kleines Lehrbuch des Positivismus. Einführung in die empirische Wissenschaftsauffassung, Den Haag 1939, nueva edición Frankfurt 1990. Herder exige que la investigación no se limite únicamente a la obra de arte, que abarque también la recepción y el comportamiento artístico en su totalidad, en otras palabras: hay que tener en cuenta siempre la práctica del arte.

27. Immanuel Kant, Werke X. Kritik der Urteilskraft und naturphilosophische Schriften 2, ed. por W. Weischedel, Wiesbaden 1957, pág. 462: «Lo bello gusta de inmediato [...] gusta sin ningún otro interés».

28. Un antagonista contemporáneo importante de Gautier fue Jean-Marie Guyau (1854-1888), el cual en su popular escrito «L'art au point de vue sociologique» (Paris 1889, $13^{\mathrm{a}}$ ed., 1923, edición alemana Leipzig 1911) indica que la relación entre obra de arte y sociedad es dialéctica. 
Con el libro Vom Musikalisch-Schönen (Sobre la Belleza Musical), publicado en el año 1854 en Leipzig, creó Hanslick la Biblia para los conciertos dentro de la vida burguesa (Bibel des Bürgerlichen Konzertlebens). Su exposición era chovinista y eurocéntrica, porque según él, la música de los pueblos indígenas era de carácter completamente natural y por lo tanto, no era música [!]; en el mejor de los casos un «primitivo grado anterior» [!] del arte musical europeo. ${ }^{29}$ Nada había frenado tan significantemente el desarrollo de la estética musical como el valor exagerado que se adjudica a los efectos de la música en los sentimientos. ${ }^{30}$

Sin embargo, también Hanslik encontraba un adversario, que era Friedrich von Hausegger. ${ }^{31}$ Interesantemente, von Hausegger enfatizó en una conferencia sobre Palestrina, dada en 1864 en Viena, que la música no era un producto de la actividad de la imaginación constructiva, sino expresión de los sentimientos. ${ }^{32}$ Para poder fundamentar esta idea buscó ayuda en las ciencias naturales. ${ }^{33}$ Después del estudio de la teoría de la evolución de Darwin, von Hausegger formula: «Después que la ciencia actual tiene como base en casi todos los ámbitos de la investigación la premisa de un desarrollo ininterrumpido, nosotros tampoco debemos ceder en la investigación de la música ante ningún obstáculo [...]. No debemos titubear en buscar los orígenes de la música hasta en épocas, en las que apenas encontramos huellas de aquello que hoy nos fascina de la música y nos parece propio de su ser [...]. Sin embargo con esto entraremos, sin darnos cuenta, en los dominios de otras ciencias, ciencias aparentemente sin ninguna relación con ella [...]. De los ámbitos adyacentes a la música, es el de las ciencias naturales el que le ha dado en los últimos tiempos las mayores aportaciones». Las raíces de la comprensión de la música se deberían desvelar allá donde «eso que hoy entendemos como arte» todavía «no se ha convertido en una contradicción tan marcada con otras ocupaciones diferentes del hombre para que se pueda comprender como un fenómeno independiente y contraponer a otros fenómenos conceptuales». ${ }^{34}$ Hausegger ve la posibilidad de acercarse a la solución de las preguntas claves sobre el surgimiento y el ser de la música por medio de la comparación animal-hombre y a través de la observación del uso de la música durante el completo desarrollo de la filogenia. ¡Qué método más

29. Véase también: Walter Graf, Zur Bedeutung der Klangfarbe im Musik-Erleben, en: Studia musicologica 11, Budapest 1969, págs. 207-225.

30. Eduard Hanslick, Vom Musikalisch-Schönen, Leipzig 1954, pág. 135.

31. Wolfgang Suppan, Franz Liszt - zwischen Friedrich von Hausegger und Eduard Hanslick, en: Studia musicologica 24, Budapest 1982, págs. 113-131; Hellmut Federhofer, Ausdruck und Rationalität. Ein Beitrag zur Musikästhetik von Friedrich von Hausegger, op. cit. 38, 1997, págs. 135-142.

32. Citado en: E.J. Danz, Die objektlose Kunst. Untersuchungen zur Musikästhetik Friedrich von Hauseggers, Regensburg 1981, pág. 33.

33. La intención de no separar metódicamente las ciencias naturales de las humanidades, sino verlas como una misma cosa, y como el «interés de los representantes de las humanidades por las ciencias naturales» son según Kurt Blaukopf algunas de las características más significativas de la rama empírica de la Historia de la Filosofía en Austria. Friedrich von Hausegger se presenta así, en mayor medida que por ejemplo Hanslick, como un destacado representante de la antigua escuela musicológica/filosófica (austriaca). Véase: Kurt Blaukopf, Pioniere empirischer Musikforschung. Österreich und Böhmen als Wiege der modernen Kunstsoziologie, Wien 1995 (Wissenschaftliche Weltauffassung und Kunst, Band 1), pág. 20; ídem., Die Orchestrierung der Wissenschaften. Otto Neuraths Konzept und die Kunstforschung, en: Philosophie, Literatur und Musik im Orchester der Wissenschaften, ed. por Kurt Blaukopf, Wien 1996, págs. 9-31.

34. Friedrich von Hausegger, Gedanken eines Schauenden. Gesammelte Aufsätze, hg. von Siegmund von Hausegger, München 1903, págs. 267-268 y 273. 
moderno, abierto al mundo, e interdisciplinario! Al contrario de Hanslick y su horizonte geográfico, histórico y desde un punto de vista sociológico evidentemente limitado, von Hausegger comenta: «El arte no le pertenece a ninguna etapa histórica determinada, a ningún pueblo elegido, a ningún ser humano privilegiado, como una propiedad exclusiva [...] no ha existido ninguna época dentro de nuestro conocimiento histórico que haya prescindido completamente de él. Encontramos sus gérmenes hasta en los primeros orígenes de la existencia humana; donde no existe huella alguna del arte, no existe ningún tipo de cultura humana». ${ }^{35}$ La base para la comprensión de estas relaciones queda, según von Hausegger, allí, donde el arte y la práctica religiosa se conjugan.

Von Hausegger distinguió dos partes de sus trabajos «antropológico musicales» (así lo diríamos hoy, porque él mismo nunca utilizó el término «antropología musical»): un ámbito psicológico, el cual trató de revelar en Die Musik als Ausdruck (La Música como Expresión), publicado en 1885 en Viena; y un ámbito fisiológico, el cual trató de mostrar en Das Jenseits des Künstlers (El Más Allá del Artista), publicado en 1893 en la misma ciudad.

En el siglo xx, Max Scheler inició una nueva etapa de la antropología filosófica con el libro Die Stellung des Menschen im Kosmos (La posición del Hombre en el Cosmos) (1928). Hasta el siglo XVII el pensamiento docto se había concentrado únicamente en el hombre como criatura a imagen y semejanza de Dios, y por entonces Descartes dio el impulso para que la filosofía se emancipara de la teología. Esta liberación del predominio teológico por Descartes sólo se pudo realizar con la creación de aquel modelo dualístico de cuerpo y alma. Eso, como una solución transitoria y a la vez condicionada temporalmente, hizo posible plantear la pregunta «QQué es el ser humano?» bajo nuevos conceptos. Estos nuevos conceptos independientes de la teoría de la imagen y semejanza de Dios permitieron plantear la cuestión y discutirla con los métodos de las ciencias empíricas. Sin embargo Scheler avanzó aún más al preguntar sobre la diferencia esencial entre ser humano y animal: «Solamente con la vista hacia el comportamiento del animal y del ser humano se puede cerrar el inmenso y absurdo abismo sobre el cual fijó la vista la filosofía desde Descartes», formuló más tarde Helmuth Plessner, el colaborador y sucesor de Scheler. ${ }^{36}$

La arriba mencionada Anthropologie der Musik (Antropología de la Música) de Helmuth Plessner (nota 4) del año 1951, desarrollada en parte ya desde $1923,{ }^{37}$ exponía, por medio del análisis del acto de tocar y cantar, las propiedades típicas del modo sensual acústico. Se trataba, concretamente, de la pregunta por qué este modo acústico era capaz de cumplir un papel de intermediario entre una forma de expresión (Kundgabe) y una forma motriz, que se manifiesta en el acto de tocar y cantar. «¿Se puede lograr esa compenetración especial entre espíritu y materia, sin rodeos a través del mundo de las cosas tan característicos para otras formas del arte - y que a veces ellas las sienten como una carga, como una reminiscencia terrenal—, sólo acústicamen-

35. Friedrich von Hausegger, Darwin und die Musik, en: ídem., Gedanken eines Schauenden..., op. cit., pág. 273.

36. Helmuth Plessner, Homo absconditus, en: Philosophische Anthropologie heute, $2^{\mathrm{a}}$. ed., München 1974, pág. 39.

37. Helmut Plessner, Die Einheit der Sinne - Grundlinien einer Äesthesiologie, Bonn 1923. 
te o también se puede lograr de otra manera, como por ejemplo pictóricamente con formas y colores? ¿O está el ejercicio musical anclado al elemento de la audición, y qué se puede aprender de este monopolio para el conocimiento del fundamento de la diversidad de los sentidos, respectivamente para la relación de lo sensitivo y de la razón?»(Plessner, pág 111-112). Las tesis de Plessner son:

1. El ser humano pertenece a los seres «productores de sonidos». Lo que le es imposible con luz y colores, lo logra en el campo de los sonidos.

2. Por razones de la posibilidad de producción primordial, la permanente conexión con las emociones, y de la situación de lejanía-cercanía el sonido era el medio más apropiado para el intercambio de señales entre los seres humanos. Con eso presupone Plessner una importante comprensión semiótica y semántico-musical, sobre todo al respecto de la «Emotional Communication». ${ }^{38}$

3. La Libertad del ejercicio musical (Freiheit des Musizierens) posibilitaría «motivar» la «sucesión a través de los mismos tonos» (Abfolge durch die Töne selbst), sin motivación de cualquier «programa», ya sea un programa poético o un modelo pictórico.

4. No por prejuicios históricos —es decir sin alusión ninguna a las evoluciones culturales, como diríamos hoy - sino «obviamente por razones de su modo» los tonos son capaces «de crear efectos a través de una sucesión de puras sensaciones, que van más allá del agrado y ya no excitan sólo el estado sino "la comprensión" del escuchar -aunque no sea la comprensión intelectual»- (Plessner, pág. 118). Aquí es decisiva la indicación de Plessner con relación a la clase de «efecto» que puede lograrse por el ejercicio musical —el autor nunca habla de «la música»-.

5. En el movimiento «asimilativo-interpretativo» (angleichend-ausdeutende Bewegung) de la danza parece palpable un tipo de transformación del contenido sensitivo y expresivo musical al movimiento corporal. «El trazado de la línea sonora crea, a través de la interrupción motriz que ella misma provoca, el carácter del haber-significar, del dar-a-entender. La interrupción y el impulso se suceden a través de la configuración musical a un mismo tiempo[...] En relación a las posibilidades de la música, el análisis del oído ha dado como resultado que tiene la capacidad única de intermediar entre una forma especial de la motricidad y una forma especial de la comprensión» (Plessner, pág. 121).

Con esto - a pesar de la «cláusula de exclusión» (Sperrklausel) de Martin Heidegger en su obra principal «Sein und Zeit» del año $1927-{ }^{39}$ se formuló la base para una antropología musical que inspiró a pensadores preparados tanto filosófica como musicológicamente, principalmente en Europa, a seguir buscando los fundamentos de la relación entre hombre y música, indagar por la pregunta del por qué y para qué requiere el ser humano la actividad musical. Se trata de los efectos de la actividad musical tanto sobre lo psíquico como lo físico, tanto sobre la

38. Helmut Staubmann, Die Kommunikation von Gefühlen. Ein Beitrag zur Soziologie der Ästhetik auf der Grundlage von Talcott Parsons' Allgemeiner Theorie des Handelns, Berlín 1995 (Soziologische Schriften 61).

39. Martin Heidegger parece casi anular la cuestión qué es el hombre; porque esa pregunta siempre había tenido como condición un entendimiento no basado en una definición científica específica. Por eso Plessner habló de una «cláusula de exclusión» («Sperrklausel») de Heidegger: la Antropología ya tomaba al hombre como hombre sin cuestionar las condiciones de esa suposición, en otras palabras, no se preguntó qué es lo que hace al hombre ser hombre. 
dinámica de la convivencia social como sobre las emociones del individuo. Se trata del entendimiento del lenguaje musical formado de manera específicamente cultural a través de las melodías, armonías, sonidos y ritmos, de la Klangrede («el habla por sonidos») en el sentido de Johann Mattheson y de Nicolaus Hanoncourt. ${ }^{40}$

Lo que sigue no son correcciones sino modificaciones, añadiduras, y principalmente confirmaciones basadas en un rico material aportado a través de investigaciones etnológicas puntuales, del comparativismo cultural y de investigaciones transdisciplinarias — un tipo de investigaciones, por cierto, que en todos los lugares se exigen por estar de moda, pero que en realidad se realizan rara vez y con temor. ${ }^{41}$

Es un hecho, sin embargo, que los representantes de la musicología histórica, la etnomusicología y en parte también de la musicología sistemática, no han cogido la pelota que les han lanzado desde la antropología filosófica —especialmente Plessner-. En Europa, la musicología comparada —cuyos padres en Berlín y Viena sí pensaban «antropológicamente», aun sin denominarlo así - todavía no se ha recuperado del trauma de la Segunda Guerra Mundial. Sólo Walter Graf en Viena llegó, a través de las raíces biológicas de la experiencia de la música, al tema de la antropología musical. ${ }^{42}$ Frank L. Harrison en Amsterdam y Hanoch Avenary en Tel Aviv recogieron datos antropológicos relacionados con la función de la música de distintos pueblos en los actos dedicados al culto. En esto, Harrison reitera el enunciado básico, que la musicología no se debería orientar en la obra sino en el hombre, ya que «the musical work of art itself» sería una ilusión: «If anthropology can be properly defined as 'the study of man as a unit in the animal kingdom', anthropomusicology [!] is the study of man's musical behaviour in the context of his total behaviour. Our study [...] should be not music in and for itself, but man in his capacity as a user of music». ${ }^{43}$ Con esto se contrapone a la estética del L'art pour l'art, una estética de la utilidad (Gebrauchsästhetik), sin que hubiera sido continuado este inicio por la musicología de habla inglesa. Quienes mostraron al contrario un interés existencial por datos antropológicomusicales, fueron los representantes de la investigación pedagógica musical —sobre todo Sigrid Abel-Struth-. Ya que, según ella, las características relevantes de la disposición psíquica, mejor dicho antropológica, para el aprendizaje musical son «las únicas condiciones que pueden proporcionar una determinación de lo posible en las exigencias de lo que deben ser los objetivos del

40. Nikolaus Harnoncourt, Musik als Klangrede. Wege zu einem neuen Musikverständnis, Salzburg 1982.

41. Richard Schwarz, Prinzipien einer interdisziplinären Forschung, op. cit.; Kurt Blaukopf, Die Orchestrierung der Wissenschaften, en: ídem. (Ed.), Philosophie, Literatur und Musik im Orchester der Wissenschaften, Wien 1996, págs. 9-31: «El postulado de la interdisciplinaridad es casi siempre aplaudido, aunque no siempre se sepa exactamente cómo realizar eso en la práctica» (pág. 9).

42. Walter Graf, Biologische Wurzeln des Musikerlebens, en: Schriften des Vereines zur Verbreitung naturwissenschaftlicher Kenntnisse in Wien, Bericht über das 107. Vereinsjahr, 1967, págs. 1-39; ídem., Das biologische Moment im Konzept der vergleichenden Musikwissenschaft, en: Studia musicologica 10, 1968, págs. 91-113; ídem., Vergleichende Musikwissenschaft. Ausgewählte Aufsätze, ed. por Franz Födermayr, Wien-Föhrenau 1980.

43. Frank Ll. Harrison, Music and Cult: The Functions of Music in Social and Religious Systems, en: Perspectives in Musicology, New York 1972, págs. 307-334, cita pág. 328. La bibliografía de Hanoch Avenary fue publicada en: ídem., Encounters of East and West in Music, Tel Aviv 1979, págs. 199-207, también en: Essays in Honor of Hanoch Avenary = Orbis Musicae X, Tel Aviv 1990/91, págs. 278-280. 
aprendizaje musical; no dicen lo que debe ser, sino que delimitan lo que puede ser». ${ }^{44}$ Reinhard Schneider, Wolfgang Schmidt-Köngernheim, Hermann Rauhe y Friedrich Klausmeier han desarrollado ulteriormente el inicio antropológico musical en la investigación y en la práctica de la pedagogía musical. ${ }^{45}$

A los escasos trabajos de pensamiento e investigación antropológica dentro de los distintos sectores de la musicología se le contraponen las constantes e incisivas preguntas de los representantes de la antropología filosófica, la sociología, la etología cultural, la biología, la teología, la psicología y fisiología médica, acerca del sentido del hacer y del escuchar música como parte del ser del humano. Pero también literatos, desde Thomas Mann $^{46}$ y Robert Musil ${ }^{47}$ hasta Thomas Bernhard $^{48}$ y melómanos y conocedores, como Ludwig Wittgenstein ${ }^{49}$ plantean sus interrogantes y manifiestan su crítica social.

El autor de estas líneas ya ha advertido varias veces sobre esos «caminantes fronterizos» de distintas especialidades académicas. ${ }^{50}$ Del lado de la filosofía pura, fue principalmente Georg Lukács, quien trató ampliamente la música como una de las «cuestiones fronterizas» (Grenzfragen) de la mímesis estética para, con eso, rebatir la ideología del L'art pour l'art de la escuela de Theodor W. Adorno. Aunque el carácter mimético de la música se hubiese rebatido, dice Lukács, quedaría fuera de duda que «sus efectos forman la base de las sensaciones humanas». ${ }^{51}$ Jürgen Habermas está convencido del poder de la obra artística musical para articular ámbitos sociales. Con esto quiere él expresar que el público burgués de los conciertos no surgió de una

44. Sigrid Abel-Struth, Ziele des Musik-Lernens. Teil I: Beitrag zur Entwicklung ihrer Theorie, Mainz 1978, págs. 20-21. (Musikpädagogik. Forschung und Lehre 12). La exigencia arriba citada es ampliada por la misma autora en: Grundriß der Musikpädagogik, Mainz 1985, págs. 149-154. Véase también: Wolfgang Suppan, Die biologischen Grundlagen und kulturellen Möglichkeiten der Talenteförderung im Bereich der Musik, mit besonderer Berücksichtigung der Situation bei den Amateurblasorchestern in Mitteleuropa, en: Florilegium Musicologicum. Hellmut Federhofer zum 75. Geburtstag, ed. por Christoph-Hellmut Mahling, Tutzing 1988, págs. 409-425.

45. Reinhard Schneider, Vorüberlegungen zu einer Anthropologie der Musik - auch in pädagogischer Absicht, en: Zeitschrift für Musikpädagogik, Heft 15, Sept. 1981, págs. 265-279; Wolfgang Schmidt-Köngernheim, Musikzauber. Außereuropäische Musik als Grundlage eines kulturanthropologischen Zugangs zur Musik im Unterricht der Sekundarstufe I, en: Praxis des Musikunterrichts, ed.. por W. Gundlach y W. Schmidt-Brunner, Mainz 1977, págs. 147-170; Friedrich Klausmeier, Die Lust, sich musikalisch auszudrücken. Eine Einführung in sozio-musikalisches Verhalten, Reinbek bei Hamburg 1978; Hermann Rauhe, Wie Volkslieder helfen und heilen können. Ein Beitrag zur musiktherapeutischen Wirkungsanalyse, en: Festschrift zum 60. Geburtstag von Wolfgang Suppan, ed. por Bernhard Habla, Tutzing 1993, págs. 251-263; véase también los ensayos de Reinhard Schneider, Wolfgang Suppan, Karl Heinrich Ehrenforth, Christoph Richter y Hermann Rauhe en: Anthropologie der Musik und der Musikerziehung, ed. por Reinhard Schneider, Regensburg 1987 (Musik im Diskurs 4).

46. Karl Heim, artículo «Thomas Mann», en: MGG 8, 1960, columnas 1587-1591.

47. Musil habla de un engreimiento burgués que piensa que la música se podría ejercer por sí misma. Véase: Robert Musil, Der Mann ohne Eigenschaften, Hamburg 1952, pág. 333.

48. Thomas Bernhard, Alte Meister, Frankfurt 1985: «Los seres humanos de nuestros días sufren, como ya no tienen otra cosa, de un consumo enfermizo de música [...] hoy se habla tanto de la inmundicia y de la química que arruinan todo, pero la música todavía arruina más que toda la inmundicia y la química [...] esa música sin pausa es lo más brutal que la humanidad de nuestros días tiene que aguantar y soportar» (págs. 277-280).

49. Wolfgang Suppan, Ludwig Wittgenstein - Denker, Lehrer, Musiker, en: Vom pädagogischen Umgang mit Musik = Zum Gedenken an Sigrid Abel-Struth, Mainz 1993, págs. 293-302.

50. Sobre todo en: Wolfgang Suppan, Der musizierende Mensch..., 1984; ídem., Musica humana..., 1986.

51. Georg Lukács, Ästhetik III, Neuwied/Darmstadt/Berlin 1963, 2a . ed., 1972, pág. 75. Lukács se refiere de nuevo a la música, sobre todo Bartók y Kodály, en su autobiografía: «Gelebtes Denken», Frankfurt am Main 1981 (= edition suhrkamp NF 88). Entre los alumnos de Lukács se cuenta a Dénes Zoltai. Véase: Dénes Zoltai, Ethos und Affekt. Geschichte der philosophischen Musikästhetik von den Anfängen bis zu Hegel, Budapest/Berlin 1970. 
metamorfosis en los estratos sociales, sino que es el cambio estructural social en el ámbito musical lo que principalmente genera el público. ${ }^{52}$ Herbert Markuse declara decididamente, que no hay obra de arte que no exprese su acto de afirmación a través del «poder de lo negativo», «que no conjure en su propia estructura las palabras, imágenes y la música de otra realidad, de otro orden, que, rechazado por el orden actual, vive en realidad en la memoria y en la esperanza de las personas». ${ }^{53} \mathrm{Y}$ hasta un pensador, anclado totalmente en otras escuelas de historia como Georg Picht, filósofo y teólogo evangélico de Heidelberg, hablando sobre Johann Sebastian Bach, llega a la conclusión - sorprendente e incómoda para muchos devotos de Bach- de que también la música de Bach es lenguaje. «Un lenguaje sólo se puede comprender, si se entiende lo que significa. Si uno goza sólo su sonido, sin tomar en cuenta su sentido, entonces ya no es lenguaje, sino nada más que ruido». ${ }^{54}$ De acuerdo a esto, la música no se puede separar de su contenido; debe ser comprendida como lenguaje. ${ }^{55}$

Tal pensamiento nos conduce inmediatamente a la estética psicológica y más adelante a

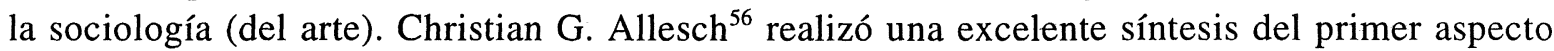
mientras que del segundo es Kurt Blaukopf a quien se le deben razonamientos básicos. ${ }^{57}$ Respecto a las relaciones entre arte, historia y sociología, es Gerhardt Kapner, sociólogo vienés, quien durante toda su vida estuvo ligado a ellas. ${ }^{58} \mathrm{Si}$ la música es, tal como lo formuló el autor de este escrito en la II hipótesis de Der musizierende Mensch ( $\mathrm{E} 1$ ser humano hacedor de música»), ${ }^{59}$ «parte del mundo simbólico del ser humano: información, comunicación, interacción», entonces la semántica (musical) debe tomarse como una parte imprescindible de una antropología musical. A una argumentación de ese tipo, se le une Vladimir Karbusicky en su Grundriß der musikalischen Semantik (Fundamentos de la Semántica Musical), cuando habla, en su preámbulo, del «pensamiento conductor antropológico» al cual estará dedicado dicho libro: «el hilo de esta obra lo forma la reconstrucción de los elementos antropológicos más relevantes de lo musical». ${ }^{60}$ Izalij I. Zemcovskij da a conocer la «escuela rusa» de la observación del quehacer y per-

52. Jürgen Habermas, Strukturwandel der Öffentlichkeit, $3^{\mathrm{a}}$ de., Neuwied 1968, pág. 51.

53. Herbert Marcuse, Konterrevolution und Revolte, Frankfurt am Main 1973, pág. 110.

54. Georg Picht, Die Dimension der Universalität von Johann Sebastian Bach, en: ídem., Hier und Jetzt. Philosophieren nach Auschwitz und Hiroshima, Stuttgart 1980, págs. 261-262.

55. Véase: Wolfgang Suppan, Johann Sebastian Bach und Johann Joseph Fux. Zur Funktion und Semantik barocker Musik, en: Kongreß-Bericht Bach-Fest Graz 1983, Kassel 1985, págs. 61-74.

56. Christian G. Allesch, Psychologie und Ästhetik - eine historische Annäherung. Untersuchungen zur historischen Entwicklung eines psychologischen Verständnisses ästhetischer Phänomene, Habil.-Schrift Salzburg 1984.

57. Kurt Blaukopf, Musical Life in a Changing Society, transl. by David Marinelli, Portland, Oregon 1992; ídem., Musik im Wandel der Gesellschaft. Grundzüge der Musiksoziologie, $2^{a}$ ed., Darmstadt 1996; ídem., Die Åsthetik Bernard Bolzanos. Begriffskritik, Objektivismus, «echte» Spekulation und Ansätze zum Empirismus, Sankt Augustin 1996. Véase también: Julius Morel y otros (Ed.), Soziologische Theorie. Abriß der Ansätze ihrer Hauptvertreter, $2^{a}$. ed., München-Wien 1992.

58. Véase: Wolfgang Suppan, War der Rattenfänger von Hameln ein Künstler? Interkulturelle Konstanten im intellektuellen und emotionalen Musik-/Kunstgebrauch, en: Kunst - Geschichte - Soziologie. Beiträge zur soziologischen Kunstbetrachtung aus Österreich. Festschrift für Gerhardt Kapner zum 70. Geburtstag, Frankfurt am Main 1997, págs. $172-185$.

59. Wolfgang Suppan, Der musizierende Mensch..., 1984, pág. 27.

60. Vladimir Karbusicky, Grundriß der musikalischen Semantik, Darmstadt 1986 (=Grundrisse 7). A parte de ello también es importante la publicación: Constantin Floros, Musik als Botschaft, Wiesbaden 1989. 
cibir musical en un sentido antropológico semántico, la cual hasta ahora casi no ha sido tomada en cuenta en occidente. ${ }^{61}$

La música influye en el comportamiento del ser humano y con ello en la dinámica de la convivencia humana. Este razonamiento exige contemplar la moderna etología que desarrolló Konrad Lorenz. En la obra de Konrad Lorenz surge, dos veces, en 1963 y en 1983, la frase: «unirse al canto significa extenderle el dedo meñique al diablo» (Mitsingen heißt dem Teufel den kleinen Finger reichen), ${ }^{62}$ esta frase que alude al efecto peligroso y sugestivo y con ello in(sub)conscientemente ideologizante, que tiene el cantar y marchar (en música marcial) juntos en el ser humano ${ }^{63}$. En el segundo libro mencionado, Konrad Lorenz llega a hablar, en la sección sobre Die Empfindungen für Harmonien (Las sensaciones para las armonías) sobre las sensaciones estéticas del hombre europeo occidental inculcadas a través de las regularidades del teclado de afinación temperada: «Se deben ofrecer repetidamente datos sensitivos, en los cuales prevalecen las reglamentaciones que han de ser percibidas, hasta que nuestro aparato receptor sea capaz de comprender dichas reglas [...] Después de "procesar" una cantidad considerable de datos se revela la imagen, como lo hace regularmente, del trasfondo de lo que antes era caótico-accidental». ${ }^{64}$ Con esto se comprueba una regla básica de la estética, de que precisamente el reconocer o, más preciso, el poder de agregar la información, es parte constitutiva del sentir lo bello (del arte). También Irenäus Eibl-Eibesfeld, en el capítulo sobre Das Schöne und Wahre: Der ethologische Beitrag zur Ästhetik (Lo Bello y lo Verdadero: la Contribución etológica para la Estética), el autor pone en claro que por medio de presentaciones artísticas, se puede tocar sobre el «teclado de las emociones humanas» para producir o quitar, para sí mismos y para los demás, estados de emoción; ya que el artista se dirige al pintar, tallar, escribir obras teatrales, poetizar o componer música, al prójimo o a seres sobrehumanos los que contempla como prójimos. Quiere influir, provocar la atención y «transmitir un mensaje ante el trasfondo de la experiencia estética pegadiza, como por ejemplo valores religiosos o ideologías políticas. Si no lo logra, su obra de arte permanece fútil». ${ }^{65}$ Eibl-Eibesfeldt proporciona, a base de resultados de investigaciones etológicas, los siguientes conocimientos:

61. Izalij I. Zemcovskij, Text - Kultur - Mensch. Versuch eines synthetischen Paradigmas, en: Festschrift zum 60. Geburtstag von Wolfgang Suppan, ed. por Bernhard Habla, Tutzing 1993, págs. 113-128.

62. Konrad Lorenz, Das sogenannte Böse, Wien 1963; ídem., Der Abbau des Menschlichen, München-Zürich 1983, pág. 188. Sobre ese tema véase también: Wolfgang Suppan, «Mitsingen heißt dem Teufel den kleinen Finger reichen» (Konrad Lorenz), en: Musik und Bildung 19, 1987, págs. 636-641; pero también «cuentos/leyendas visualizados y/o (instrumentos de) música» son capaces de tener un efecto semejante al de la música; véase ídem., Hameln ist überall. Musik in Karikatur/Cartoon und Plakatkunst, en: Österreichische Zeitschrift für Volkskunde XLIX/98, Wien 1995, págs. 41-55.

63. A la cuestión de las relaciones entre música y política uno de mis cooperadores aportó publicaciones esenciales: Helmut Brenner, Musik als Waffe? Theorie und Praxis der politischen Musikverwendung, dargestellt am Beispiel der Steiermark 1938-1945, Graz 1992; ídem., Música Ranchera. Das mexikanische Äquivalent zur Country and Western Music aus historischer, musikalischer und kommerzieller Sicht, Tutzing 1996 (Musikethnologische Sammelbände 14).

64. Konrad Lorenz, Das sogenannte Böse..., pág. 135.

65. Irenäus Eibl-Eibesfeldt, Die Biologie des menschlichen Verhaltens. Grundriß der Humanethologie, München/Zürich 1984, págs. 826-827. y 831. La siguiente tesis de doctorado en filosofía también fue supervisada, en Munich, por Eibl-Eibesfeldt: Rainer Eggebrecht, Sprachmelodische und musikalische Forschungen im Kulturvergleich. Ein interdisziplinär-anthropologischer Ansatz, 1985. 
1. De forma más directa que las artes dramáticas, visuales y habladas, la música se dirige a las emociones y con ello a partes de la vida emocional del ser humano reguladas por el subconsciente.

2. Existen «ritmos basales» que influyen específicamente el comportamiento humano y eso en todas las culturas en forma similar: algunos ritmos excitan, otros relajan.

3. Con la repetición constante de un ritmo o de un motivo sonoro/melódico se pueden evocar situaciones de trance, de éxtasis.

4. Los textos cantados se memorizan con mayor facilidad que los textos hablados. Por ello las canciones son más aptas «para la indoctrinación política y para la enseñanza».

5. La música está a menudo al servicio de la formación grupal. ${ }^{66}$

Generalmente, la antropología musical aprende de la etología cultural que habría que hacer una diferencia entre la evolución biológica singular y las muchas evoluciones culturales. Esto significa: a un lado hay fenómenos tales - tanto en la práctica musical como en el uso mismo de la música - que están basados en el sustrato biológico del hombre y que, por consiguiente, pueden encontrarse de manera independiente en todas las culturas y afectan a todos los hombres de igual manera; al otro lado hay aquellos fenómenos que fueron encontrados y determinados dentro de una cultura específica. Los primeros están ligados intrínsecamente al ser humano, los segundos son aprendidos por el hombre y asimismo éste se puede desprender de ellos. ${ }^{67}$

Gerhard Harrer y sus colaboradores de Salzburgo, con sus Grundlagen der Musiktherapie und Musikpsychologie (Fundamentos de la Terapia y Psicología Musical) también aportaron materiales esenciales para la antropología musical. ${ }^{68}$ La Fundación «Herbert von Karajan» fomentó la investigación sobre este tema de una manera extraordinaria. ${ }^{69}$ Los escritos y las ediciones de M. Clynes y Nils L. Wallin conducen hacia la biología y la medicina, y sobre todo hacia la neurología. ${ }^{70}$ La idea teológico-antropológica de que «la vida humana estaría determinada irremediablemente por los aspectos religiosos» ${ }^{71}$ coincide perfectamente con los conceptos arriba mencionados, asimismo de las religiones de los pueblos indígenas como las de las culturas clásicas, que

66. Wolfgang Suppan, Menschen- und/oder Kulturgüterforschung (?). Über den Beitrag der Musikwissenschaft zur Erforschung menschlicher Verhaltensformen, en: Studien zur Systematischen Musikwissenschaft (Karbusicky-Festschrift) = Hamburger Jahrbuch für Musikwissenschaft 9, 1986, págs. 37-66.

67. Wolfgang Suppan, Biologische und kulturelle Bedingungen des Musikgebrauches, en: Kongreß-Bericht Bayreuth 1981, Kassel 1984, págs. 618-622. Una versión abreviada de ello se publicó en: Universitas 37, 1982, págs. 1279-1284); ídem., Biologische Voraussetzungen und Grenzen kultureller Traditionsbildung, en: Traditiones $19=$ Gedenkschrift für Valens Vodusek, Ljubljana 1990, págs. 145-165.

68. Gerhard Harrer (Ed.), Grundlagen der Musiktherapie und Musikpsychologie, Stuttgart 1975.

69. W. C. Simon (Ed.), Mensch und Musik. Festschrift für Herbert von Karajan, Salzburg 1979; véase también: Wolfgang Suppan, Musik und Neurophysiologie, en: Musik und Bildung 14, 1982, págs. 586-589.

70. M. Clynes (Ed.), Music, Mind, and Brain, New York/London 1982; Nils L. Wallin, Further Remarks on a Biological Approach to Musicology, en: Trends and Perspectives in Musicology, Stockholm 1985, págs. 12-34; R. Spintge y R. Doh (Ed.), Musik in der Medizin, Grenzach/Wyhlen 1985. También importante al respecto es: Hans Fritz, Kastratengesang. Hormonelle, konstitutionelle und pädagogische Aspekte, Tutzing 1994 (Musikethnologische Sammelbände 13).

71. Wolfhart Pannenberg, Anthropologie in theologischer Sicht, Göttingen 1983, pág. 7; O. H. Pesch, Frei sein aus Gnade. Theologische Anthropologie, Freiburg 1984. 
la música es el lenguaje de los dioses. En el cristianismo aparecen cantos «causados por el Espíritu Santo [...], una señal escatológica, parte de la eterna alabanza de los ángeles y los santos». ${ }^{72}$

La enumeración de todos estos hechos testifica: primero, lo limitada que es la idea estadounidense, del denominado concepto antropológico cultural de la «Anthropology of Music» - como lo llamó Merriam en 1964-;33 segundo, lo restringida que ven la especialidad los autores de los ensayos sobre el «Comparative Musicology and Anhropology of Music», editados por Bruno Nettl y Phillip V. Bohlman $;{ }^{74}$ y tercero, lo ajustada que es la metodología y la base de material para la definición de las «Music Anthropologies» (como lo llaman — jen plural! — en el Journal of the American Musicological Society 1995). ${ }^{75}$

En contra de ello, yo siempre he intentado mostrar, que la comprensión de «Use and Function» de la música en los pueblos indígenas y de las antiguas culturas clásicas, por cierto, es la premisa para la comprensión de la relación ser humano-música en el pasado y en el presente pero que los resultados puntuales de las específicas investigaciones de campo de la etnomusicología, sin duda alguna, son una condición necesaria para ello. Sin embargo, la recopilación positivista de datos y hechos sólo nos habla en base a comparaciones genéticas y tipológicas así como en base a análisis sincrónicos. ${ }^{76}$ Por último, agregar estos datos inteligentemente a los conocimientos generales de las humanidades y las ciencias naturales es la llave que nos permite acceder a la respuesta de la pregunta: ¿qué es el hombre y de qué es capaz?; en otras palabras, cumplir con las exigencias de una antropología pragmática (de la música).

Éste es el resumen - muy personal, pero sólo parcialmente subjetivo- de 25 años de esfuerzos en el estudio de la antropología musical, porque fue en 1973 que el autor de estas líneas ofreció por primera vez en una universidad de habla alemana, para ser preciso, en el seminario de musicología de la Universidad de Mainz, una asignatura denominada «Antropología Musical». También su clase inaugural en Graz en 1974 estuvo dedicada al mismo tema. ${ }^{77}$ En ese sentido hay que mencionar que para el autor se abrió ese camino hacia un pensamiento antropológico proveniente de Tomás de Aquino y Edmund Husserl a través de su profesor de filosofía sistemática en Graz, Amadeus von Silva Taronca. Sin embargo, el giro hacia el tema fue provocado por el filósofo Franz Koppe, hoy en Berlín - anteriormente en Konstanz-: En el verano de

72. Philipp Harnoncourt, «So sie's nicht singen, so gleuben sie's nicht». Singen im Gottesdienst. Ausdruck des Glaubens oder liturgische Zumutung?, en: Liturgie und Dichtung, ed. por H. Becker y R. Kaczynski, Tomo 2, St. Ottilien 1983, págs. 150-153. Véase también: Päivikki Suojanen, Finish Folk Hymn Singing. Study in Music Anthropology, Tampere 1984.

73. Véase nota núm. 6.

74. Bruno Nettl/Philip V. Bohlman, Comparative Musicology and Anthropology of Music. Essays on the History of Ethnomusicology, Chicago 1991.

75. Véase nota núm. 9.

76. Viktor Schirmunski, Vergleichende Epenforschung 1, Berlin 1961; Wolfgang Suppan, Volkslied. Seine Sammlung und Erforschung, Stuttgart 1966 (Sammlung Metzler. Realienbücher zur Literatur, Band 52), $2^{\mathrm{a}}$ ed. Stuttgard 1978, pág. 27.

77. Wolfgang Suppan, Werkzeug - Kunstwerk - Ware. Prolegomena zu einer anthropologisch fundierten Musikwissenschaft, en: Musikethnologische Sammelbände 1, Graz 1977, págs. 9-20. 
1971, nos encontramos por casualidad en un balneario de Bad Dürnheim. Durante estas 4 semanas realizamos paseos de varias horas en el sur de la Selva Negra, en los cuales Koppe una y otra vez insistía en encontrar una respuesta a la pregunta sobre el sentido y sobre la función del quehacer musical. ${ }^{78} \mathrm{El}$ autor de estas líneas, como musicólogo historiador, no estaba preparado en absoluto para tales preguntas, pero ya no pudo desprenderse de ellas. Un impulso más en la misma dirección se logró poco después de que el autor hubiese logrado el rango académico de catedrático (Habilitation) en el año de 1971: Después de los disturbios estudiantiles de 1968 un círculo de estudiantes de Mainz, particularmente crítico, exigía escuchar más acerca del poder emocional y del efecto social de la música que del «conocimiento enciclopédico de estilo MGG» - tal como ellos lo llamaron. Ahora la antropología musical, que en la primera edición de la MGG todavía no fue mencionada, ya se ha convertido ella misma en un «conocimiento enciclopédico de estilo $M G G »{ }^{79}$

78. De Franz Koppe se publicaron más tarde: Grundbegriffe der Ästhetik, Frankfurt am Main 1983 (edition Suhrkamp NF 160). En esa publicación él argumenta «contra la ocultación de la relación entre el arte y la vida en insignificantes teorías de L'art pour l'art», (pág. 20); Kunst und Bedürfnis. Ein Ansatz zur sprachlichen Wiederaufnahme systematischer Ästhetik, en: Kolloquium Kunst und Philosophie 1, ed. por W. Oelmüller, Paderborn 1981, págs. 74-93; Mimetischer Schein, imaginärer Schein, schöner Schein - und was davon bleibt, en: Kolloquium Kunst und Philosophie 2, Paderborn. 1982, págs. 126-130.

79. Wolfgang Suppan, artículo «Musikanthropologie», en: MGG, 2ª ed., Sachteil 6, Kassel. 1997, columnas 921-929. 